\title{
Maximum Degradation Rates in Vinyl Polymers
}

\author{
K. KISHORE AND V. A. BHANU, Department of Inorganic and Physical \\ Chemistry, Indian Institute of Science, Bangalone 560 012, India
}

The thermal and thermo-oxidative degradation of thermoplastic vinyl polymers has been studied extensively. However, there are several features which are either controversial or not understood clearly. From dynamic thermogravimetric (TG) studies in our laboratory we have observed that in thermo-oxidative degradation, although it starts at lower temperatures compared to thermal degradation, the rate of main degradation (between 20 and $80 \%$ ) is always higher in the latter case. Such an observation borne out by a few literature TG curves, but no explanation whatsoever is available for this anomaly. In this letter we attempt to carry out a systematic TG study on few vinyl polymers in $\mathrm{N}_{2}$ and $\mathrm{O}_{2}$ to explain this behavior. It may be pointed out that here we deal with an empirical comparison of the overall average degradation data (based on dynamic TG), which do not represent a comparison of the actual degradation rates based on the main chain links of the polymers.

\section{EXPERIMENTAL}

The thermogravimetric analysis was carried out using Stanton Redcroft TG $750 / 770$ instrument. The gases $\left(\mathrm{O}_{2}\right.$ or $\left.\mathrm{N}_{2}\right)$ were flushed at a rate of $25 \mathrm{~mL} / \mathrm{min}$. A sample weight of $3-7 \mathrm{mg}$ and a heating rate of $3^{\circ} \mathrm{C} / \mathrm{min}$ were maintained in all runs. This low heating rate was used in the present work so that adequate thermal equilibrium would be maintained between the sample and the heating assembly. The polymers studied were polypropylene (PP), poly(1-butene) (PB), and polystyrene (PS).

\section{RESULTS AND DISCUSSION}

The overall polymer degradation reaction can be represented as follows:

$$
A_{\text {(oolid) }} \rightarrow B_{\text {(rolid) }}+C_{\text {(gas) }}
$$

for which the general rate equation is

$$
\frac{d x}{d t}=k(1-x)^{n}
$$

where $k$ is the rate constant, $n$ is the order of the reaction, and the fraction $x$ of the overall degradation occurring at any time $t$ is expressed as

$$
x=\frac{\left(W_{0}^{\prime}-W^{\prime}\right)}{W_{0}^{\prime}}
$$

where $W_{0}^{\prime}=W_{0}-W_{r}, W_{0}$ being the initial weight of the sample, $W_{r}$ the inactive weight of the residue, and $W^{\prime}=W-W_{r}$, with $W$ the weight of the sample at temperature $T(K)$ and time $t$. 
Equation (3) is obtained by introducing the heating rate $(\phi=d x / d T)$ and the Arrhenius equation $\left(k=A e^{-E / R T}\right)$ in eq.(1):

$$
\frac{d x}{d T}=\frac{A}{\phi}(1-x)^{n} e^{-E / R T}
$$

Upon applying the conditions for the maximum rate $\left(d^{2} x / d T^{2}=0\right)$, eq.(3) yields

$$
\left(\frac{d x}{d T}\right)_{m}=\frac{E\left(1-x_{m}\right)}{n R T_{m}^{2}}
$$

where $E$ is the activation energy of degradation, $R$ is the gas constant, and $x_{m}$ and $T_{m}$ represent the fraction of overall average degradation that has occurred and the temperature (in $\mathrm{K}$ ), respectively, corresponding to the maximum rate $(d x / d T)_{m}$, of degradation. For convenience, we call eq. (4) the maximum rate equation in the text. The maximum rate of overall degradation can be calculated from eq.(4), provided $E$ and $n$ are known, while $x_{m}$ and $T_{m}$ can be obtained from a dynamic TG run.

The literature $E$ and $n$ values for PP, PB, and PS are given in Table I except for thermal degradation of $\mathrm{PB}$ owing to the lack of any reported value. It may be pointed out that in the literature the kinetic studies on polymer degradation mostly center around evaluation of activation energy without paying much attention to the frequency factor or order of reaction. In the absence of authentic $n$ values for the polymers used in the present study, the order of reaction was taken as unity. It has been reported that thermoplastic polymer degradation generally follows first-order kinetics. ${ }^{2}$ From the literature, the average value of $E$ was derived from the range of similar $E$ values quoted by various authors (see Table I). The $E$ values for PP, PS, and other similar polymers are in the range of $50-70 \mathrm{kcal} / \mathrm{mol}$ for thermal degradation. An approximate value of $60 \mathrm{kcal} / \mathrm{mol}$ was therefore taken for the thermal degradation of PB.

TABLE I

Activation Energies for Polymer Degradation from Literature

\begin{tabular}{ccl}
\hline Polymer & Atmosphere & \multicolumn{1}{c}{${\text { Activation energy }{ }^{\mathrm{b}, c}(\mathrm{kcal} / \mathrm{mol})}^{-1}$} \\
\hline PP & $\mathrm{O}_{2}$ & $15.7(3), 9.6,34.4,32.4(4), 22.6,24.9(5), 25(6)$ \\
& $\mathrm{N}_{2}$ & $50.1(7), 63.8,54.4(5), 68(8), 58,55,62.5(9), 58,54(10), 56(11)$, \\
& $68.1(12), 52.8,24.7(13)$ \\
PB & $\mathrm{O}_{2}$ & $28(6)$ \\
PS & $\mathrm{N}_{2}$ & $58(16), 44.7(17), 65(18), 42.5(19), 50(20), 60(21), 45(22)$, \\
& & $30(15), 35(23), 78(10), 70(24), 74(11)$. \\
& $\mathrm{O}_{2}$ & $29(14), 30(15)$
\end{tabular}

- The values in parentheses indicate the reference.

- Activation energy values for experiments done in vacuum are cumulated with $\mathrm{N}_{2}$ while those obtained for experiments done in air are cumulated with $\mathrm{O}_{2}$.

- A solid line below the energy value indicates a common reference given next to the last value. 
TG thermograms of polymers are shown in Figure 1 in $\mathrm{N}_{2}$ and $\mathrm{O}_{2}$. From numerous $x$ and $T$ values the average rates at various temperatures are calculated by using the equation

$$
\frac{d x}{d T}=\frac{x_{2}-x_{1}}{T_{2}-T_{1}}
$$

The successive values of $x$ and $T(K)$ are chosen from experimental TG curve at the smallest possible intervals, so the above approximation is valid. The maximum rate $(d x / d T)_{m}$ and corresponding $x_{m}$ and $T_{m}$ (the average of the two $x$ 's and $T$ 's used to calculate $(d x / d T)_{m}$ by using eq.(5)) are obtained by using a simple FORTRAN program run on a DEC-1090 computer. The maximum rate so obtained is designated as the experimental $(d x / d T)_{m}$ and is listed in Table II. From these $x_{m}$ and $T_{m}$ values and the average $E$ values (Table II), $(d x / d T)_{m}$ is calculated by using the maximum rate equation for $n$ taken to be unity. These are presented as calculated $(d x / d T)_{m}$ values in Table II. In the case of oxidative degradation of PP and PS, although the reaction involves two steps, only the first step is considered for evaluating $(d x / d T)_{m}$ since the second step involves degradation of char.

Table II shows that the calculated $(d x / d T)_{m}$ is always higher in $\mathrm{N}_{2}$ compared to $0_{2}$. The experimental $(d x / d T)_{m}$ shows similar behavior. Thus it can be said that for the polymers examined in the present investigation, maximum rate values in $\mathrm{N}_{2}$
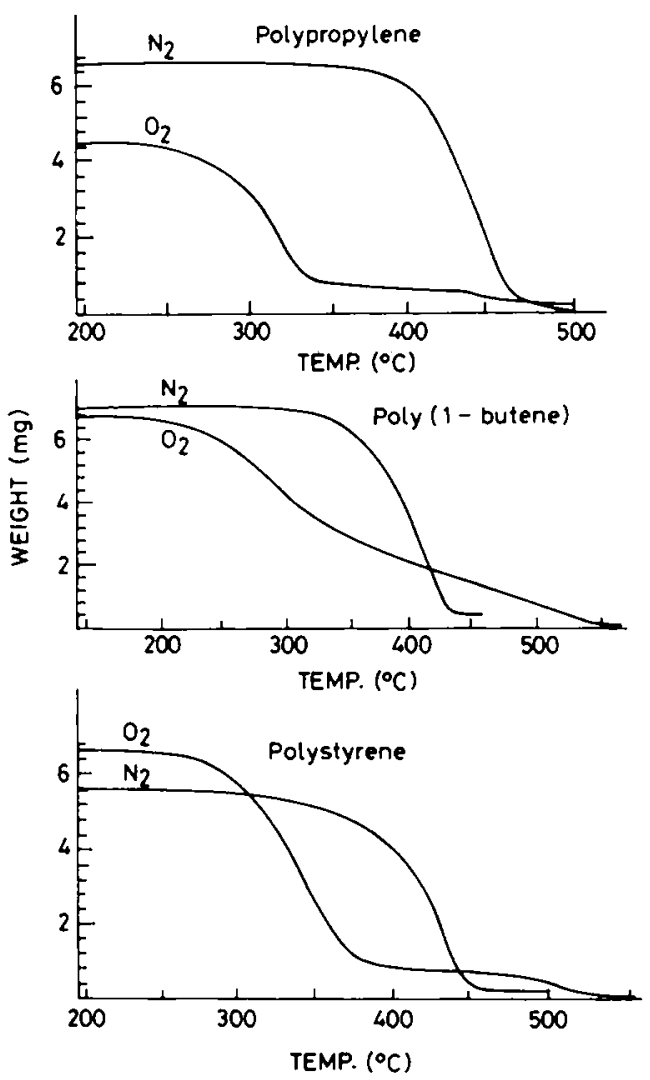

Fig. 1. TG traces of polymers in $\mathrm{O}_{2}$ and $\mathrm{N}_{2}$. 
TABLE II

Comparative Values of Maximum Degradation Rate of Different Polymers

\begin{tabular}{|c|c|c|c|c|c|c|}
\hline \multirow[b]{2}{*}{ Polymer } & \multicolumn{2}{|c|}{$\begin{array}{c}\text { Average value of } \\
\text { activation energy } \\
\text { (kcal/mol, from Table I) }\end{array}$} & \multicolumn{2}{|c|}{$\begin{array}{l}(d x / d T)_{m} \times 10^{-2} \\
\text { in } \mathrm{O}_{2} \text { atmosphere }\end{array}$} & \multicolumn{2}{|c|}{$\begin{array}{l}(d x / d T)_{m} \times 10^{-2} \\
\text { in } N_{2} \text { atmosphere }\end{array}$} \\
\hline & $\begin{array}{c}\mathrm{O}_{2} \\
\text { atmosphere }\end{array}$ & $\begin{array}{c}\mathrm{N}_{2} \\
\text { atmosphere }\end{array}$ & Calculated & Experimental & Calculated & Experimental \\
\hline PP & 23.50 & 55.57 & 0.65 & 2.37 & 3.35 & 2.93 \\
\hline PB & 28.00 & 60.00 & 2.82 & 0.70 & 3.38 & 1.85 \\
\hline PS & 29.50 & 54.35 & 1.94 & 1.86 & 2.05 & 2.24 \\
\hline
\end{tabular}

are always higher than in $\mathrm{O}_{2}$. Thermograms reported by Brauman ${ }^{1}$ show a similar trend. A close look at the calculated and experimental values of $(d x / d T)_{m}$ (Table II) shows that they are comparable in a few cases, but deviations occur in others. The exact reasons for this mismatch are difficult to pinpoint at this stage. However, it is likely that it might be due to the assumption that $n$ is unity in all cases. Accurate calculation of $n$ is therefore needed to throw light on this aspect.

The present results have obvious implications for the study of thermal and thermooxidative degradation of vinyl polymers. That the initiation in oxidative degradation is much easier compared to thermal degradation is obvious. This leads to the conclusion that faster $(d x / d T)_{m}$ in $\mathrm{N}_{2}$ is related to the propagation step. Investigations of the propagation step of thermal and thermo-oxidative degradation may perhaps yield fruitful information and increase our understanding of the degradation mechanism of vinyl polymers.

The authors sincerely thank Mrs. R. Vasanthakumari for recording the TG runs, Mr. R. Nagarajan for providing the computer program, and Dr. K. Mohandas for helpful discussions.

\section{References}

1. S. K. Brauman, J. Fire Retard. Chem., 3, 138 (1976).

2. B. Rabinovitch, in Tenth Symposium (International) on Combustion, The Combustion Institute, Pittsburgh, 1965, pp. 1395-1404.

3. A. A. Ivanov, A. P. Firsov, V. D. Grigoryan, and A. A. Berlin, Chem. Abstr., 71:61836q (1969).

4. K. Y. Gel and C. C. Rim, Chem. Abstr., 88:121872m (1978).

5. Z. Osawa, Chem. Abstr.,68:30350K (1968).

6. L. Reich and S. Stivala, Autooxidation of Hydrocarbons and Polyolefins, Dekker, New York, 1969, Chap. 8.

7. N. Grassie and W. B. H. Leeming, Eur. Polym. J., 11, 809 (1975).

8. T. E. Davies, R. L. Tobias, and E. B. Peterli, J. Polym. Sci, 56, 485 (1962).

9. L. Reich, J. Appl. Polym. Sci., 10, 465 (1966).

10. L. Reich, J. Appl. Polym. Sci., 10, 813 (1966).

11. L. Reich, J. Appl. Polym. Sci., 11, 161 (1967).

12. S. Kiyoshi and H. Nishizaki, Chem. Abstr., 89:164248a (1978).

13. O. Yoshiro and M. Kazuo, Chem. Abstr., 69:97330t (1968).

14. V. N. Esenin, I. A. Krasotkina, and V. M. Gol'dberg, Chem. Abstr., 93:72440m (1980).

15. K. Kishore and V. R. Pai Verneker, J. Polym. Sci. Polym. Chem. Ed., 14, 761 (1976).

16. S. L. Madorsky, J. Polym. Sci., 11, 491 (1953).

17. H. H. G. Jellinek, J. Polym. Sci., 10, 506 (1953).

18. P. D. Zemany, Nature, 171, 391 (1953).

19. D. R. Bain, Chem. Abstr., 77:35179g (1972).

20. E. Atherton, J. Polym. Sci., 5, 378 (1950). 
21. D. A. Anderson and E. S. Freeman, J. Polym. Sci., 54, 253 (1961).

22. H. H. G. Jellinek, J. Polym. Sci., 4, 13 (1949).

23. A. W. Coats and J. P. Redfern, J. Polym. Sci. B, 3, 917 (1965).

24. L. Reich, J. Appl. Polym. Sci., 10, 1033 (1966).

Received April 181985

Accepted April 23, 1985 